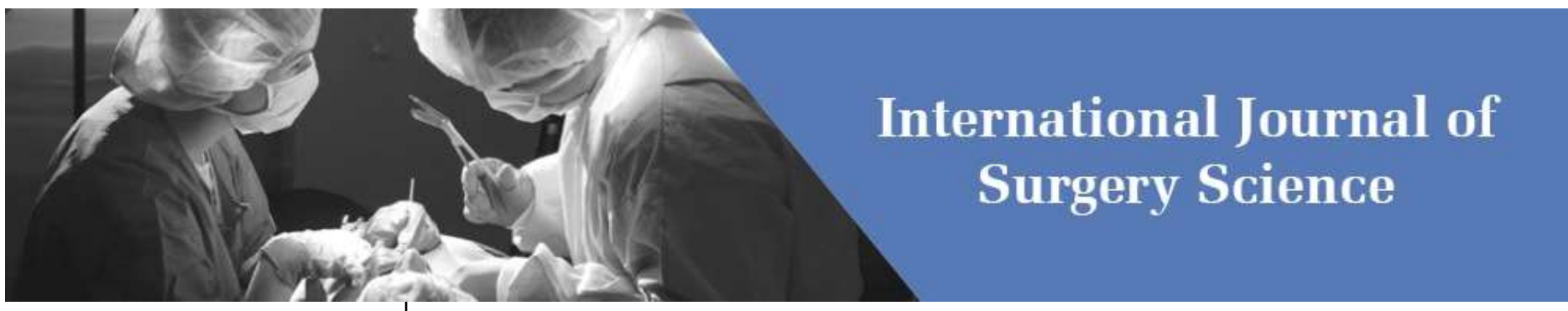

E-ISSN: 2616-3470

P-ISSN: 2616-3462

(c) Surgery Science

www.surgeryscience.com

2020; 4(4): 281-282

Received: 18-02-2020

Accepted: 27-04-2020

Dr. Amith Kiran B

Professor, Department of General Surgery, Srinivas Institute of

Medical Sciences, Mangalore.

Karnataka, India
Corresponding Author: Dr. Amith Kiran B

Professor, Department of General Surgery, Srinivas Institute of Medical Sciences, Mangalore.

Karnataka, India

\section{A study of chest trauma}

\section{Dr. Amith Kiran B}

DOI: https://doi.org/10.33545/surgery.2020.v4.i4e.572

\section{Abstract}

Motor vehicle accidents are the most common cause of traumatic chest injuries. Early arrival to the hospital improves the chances of survival. Patients already in shock at the time of arrival to hospital have poor prognosis. There is an increase in traumatic chest injuries in the present days due to increase in road traffic accidents and violence in various forms. Chest trauma cases are usually associated with other injuries also. The most common being head injury, which also incidentally is the most common cause of death in many patients. Complete evaluation of the patient and early intervention can reduce the mortality and morbidity.

Keywords: Chest trauma, study, cross sectional study

\section{Introduction}

Thoracic trauma directly accounts for approximately $25 \%$ of trauma-related mortality and is a contributing factor in another $25 \%$. Fortunately, over $80 \%$ of injuries can be managed nonoperatively utilising tube thoracostomy, appropriate analgesia and aggressive respiratory therapy. The World Health Organisation (WHO) documented over 300,000 deaths in 2008 (9\% of all world deaths) ${ }^{[1,2,3]}$. There is an increase in traumatic chest injuries in the present days due to increase in road traffic accidents and violence in various forms. Chest trauma cases are usually associated with other injuries also ${ }^{[4,7]}$. The most common being head injury, which also incidentally is the most common cause of death in many patients ${ }^{[8,9]}$. Motor vehicle accidents are the most common cause of traumatic chest injuries. Early arrival to the hospital improves the chances of survival. Patients already in shock at the time of arrival to hospital have poor prognosis. There is an increase in traumatic chest injuries in the present days due to increase in road traffic accidents and violence in various forms. Chest trauma cases are usually associated with other injuries also ${ }^{10}$. The most common being head injury, which also incidentally is the most common cause of death in many patients. Complete evaluation of the patient and early intervention can reduce the mortality and morbidity ${ }^{[11,12]}$. Complete evaluation of the patient and early intervention can reduce the mortality and morbidity ${ }^{[13]}$. At the same time, the knowledge about when to intervene and when to adopt an observation approach is also important.

\section{Aims and Objectives}

To study the patients with chest trauma.

\section{Materials and Methods}

This study was done in the Department of Surgery at Srinivas Institute of medical Sciences, Mangalore.

This study was done from Feb 2018 to March 2019.

Twenty-one cases was the sample size of the study.

The signs and the symptoms were noted.

The type of injury, treatment modality and the mortality rate has been noted and described.

\section{Results}

Table 1: Age Distribution:

\begin{tabular}{|c|c|}
\hline $20-30$ years & 11 \\
\hline $31-40$ years & 07 \\
\hline 41-50 years & 03 \\
\hline 51-60 years & 09 \\
\hline
\end{tabular}




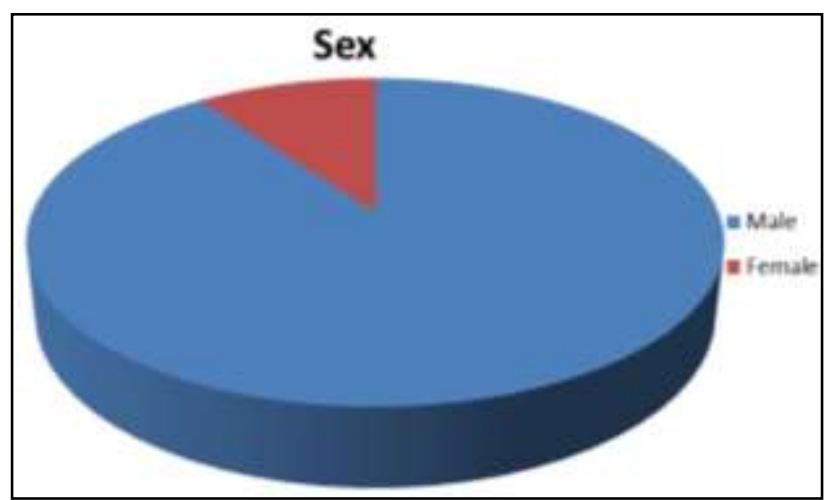

Fig 2: Sex Distribution:

Table 2: Cause of the Injury

\begin{tabular}{|c|c|}
\hline RTA & 23 \\
\hline Fall from height & 02 \\
\hline Stab injury & 01 \\
\hline Run over (Compression) & 03 \\
\hline Blast & 01 \\
\hline
\end{tabular}

Table 3: Injury

\begin{tabular}{|c|c|}
\hline Soft tissue Injury & 14 \\
\hline Multiple rib fracture & 07 \\
\hline Haemo/pneumothorax & 03 \\
\hline Mediastinal emphysema & 01 \\
\hline Lung Injury & 03 \\
\hline Heart Injury & 01 \\
\hline Diaphragmatic Injury & 01 \\
\hline Sucking wounds & 02 \\
\hline Flail chest & 01 \\
\hline
\end{tabular}

Table 4: Intervention:

\begin{tabular}{|c|c|}
\hline ICTD & 03 \\
\hline Thoracotomy & 05 \\
\hline Laparotomy & 01 \\
\hline Tracheostomy & 18 \\
\hline Laparotomy and Thoracotomy & 01 \\
\hline
\end{tabular}

Table 5: Other Line of treatment

\begin{tabular}{|c|c|}
\hline Shock & 24 \\
\hline Blood transfusion & 19 \\
\hline Soft tissue and Ortho & 11 \\
\hline Ventilatory support & 09 \\
\hline
\end{tabular}

Table 6: Mortality

\begin{tabular}{|c|c|}
\hline Death & 07 \\
\hline First 24 hours & 04 \\
\hline
\end{tabular}

\section{Discussion}

The thoracic cavity contains three major anatomical systems: the airway, lungs, and the cardiovascular system. As such, any blunt or penetrating trauma can cause significant disruption to each of these systems that can quickly prove to be life threatening unless rapidly identified and treated. Chest trauma accounts for approximately $25 \%$ of mortality in trauma patients ${ }^{[1,2]}$. This rate is much higher in patients with polytraumatic injuries. 85$90 \%$ of chest trauma patients can be rapidly stabilized and resuscitated by a handful of critical procedures. Trauma patients are commonly encountered in all emergency departments, not just in specified trauma centers. For this reason, emergency medicine providers should be prepared to appropriately evaluate, resuscitate and stabilize any patient with chest trauma.

Unlike other disease entities, trauma patients often present with a known traumatic mechanism such as a car collision, fall, gunshot or stab wound. In rare cases, a patient may present in a state of significant altered mental status and be unable to provide any significant history. In these situations, certain physical examination clues to the presence of trauma include findings such as contusions, lacerations, or deformities. Palpation of crepitus over the chest wall may also be appreciated.

In patients who are awake and lucid, the chest trauma may present with chest pain, dyspnea, back or abdominal pain, and occasionally syncope. Unstable chest trauma patients may show signs of severe respiratory distress or profound shock requiring emergent resuscitation. Unstable chest trauma patients can also deteriorate to the point of traumatic arrest and depending on the mechanism of chest trauma, may be candidates for an emergent ED thoracotomy.

Thoracic trauma can be distinguished by the mechanism of injury. Blunt trauma refers to mechanisms causing increased intrathoracic pressure such as car collisions (most common cause of thoracic trauma), and falls. By comparison, penetrating trauma largely refers to gunshots, stab wounds, and occasionally impalement. There is considerable overlap amongst the various traumatic disorders experienced in both penetrating and blunt chest trauma. However, in comparison to penetrating trauma, blunt chest trauma patients may have a more subtle presentation with less obvious physical exam findings.

\section{Conclusion}

There is an increase in traumatic chest injuries in the present days due to increase in road traffic accidents and violence in various forms. Chest trauma cases are usually associated with other injuries also. The most common being head injury, which also incidentally is the most common cause of death in many patients. Complete evaluation of the patient and early intervention can reduce the mortality and morbidity.

\section{References}

1. ATLS: Advanced Trauma Life Support for Doctors (Student Course Manual). Ninth ed. American College of Surgeons 2013.

2. Bernardin B, Troquet JM. Initial management and resuscitation of severe chest trauma. Emergency Medicine Clinics of North America 2012;30:377.

3. Martinez ARJ, Voth HA, Fernandez MC, et al. Evolution and complications of chest trauma. Arch Bronchopneumol 2013;49(5):177-180.

4. LoCicero J, Mattox KL. Epidemiology of chest trauma. Surg Clin North Am 1989;69(1):15-19.

5. Chaturvedi RK, Mishra A, Chaturvedi P. Pattern of head injuries in fatal road traffic accidents in Indore region, MP. JEMDS 2014;3(21):5645-5651.

6. Ammons MA, Moore EE, Rosen P. Role of the observation unit in the management of thoracic trauma. J Emerg Med 1986;4(4):279-282.

7. David B, Mark S. Pediatric thoracic trauma. Critical Care Medicine 2002;30(11):S409-S415.

8. Beal SL, McKennan M. Blunt diaphragm rupture: a morbid injury. Arch Surg 1988;123(7):828-832.

9. Fabian TC, Mangiante EC, Patterson CR, et al. Myocardial contusion in blunt trauma: clinical characteristics, means of diagnosis, and implications for patient management. J trauma 1988;28(1):50-57.

10. Bodai BI, Smith JP, Ward RE, et al. Emergency thoracotomy in the management of trauma. JAMA 1983;249(14):1891-1896.

11. Etoch SW, Bar-Natan MF, Miller FB. Tube thoracostomy. Factors related to complications. Arch Surg 1995;30(5):521-525. 